\title{
Bronchospasm and its biophysical basis in airway smooth muscle Jeffrey J Fredberg*
}

Address: Harvard School of Public Health, 665 Huntington Avenue, Boston, MA 02115, USA

Email: Jeffrey J Fredberg* - jfredber@hsph.harvard.edu

* Corresponding author

Published: 26 February 2004

Respiratory Research 2004, 5:2
Received: 03 September 2003

Accepted: 26 February 2004

This article is available from: http://respiratory-research.com/content/5/I/2

(C) 2004 Fredberg; licensee BioMed Central Ltd. This is an Open Access article: verbatim copying and redistribution of this article are permitted in all media for any purpose, provided this notice is preserved along with the article's original URL.

\begin{abstract}
Airways hyperresponsiveness is a cardinal feature of asthma but remains unexplained. In asthma, the airway smooth muscle cell is the key end-effector of bronchospasm and acute airway narrowing, but in just the past five years our understanding of the relationship of responsiveness to muscle biophysics has dramatically changed. It has become well established, for example, that muscle length is equilibrated dynamically rather than statically, and that non-classical features of muscle biophysics come to the forefront, including unanticipated interactions between the muscle and its time-varying load, as well as the ability of the muscle cell to adapt rapidly to changes in its dynamic microenvironment. These newly discovered phenomena have been described empirically, but a mechanistic basis to explain them is only beginning to emerge.
\end{abstract}

\section{Introduction}

It is self-evident that acute narrowing of the asthmatic airway and shortening of the airway smooth muscle are inextricably linked. Nonetheless, it was many years ago that research on the asthmatic airway and research on the biophysics of airway smooth muscle (ASM) had a parting of the ways [1]. The study of smooth muscle biophysics took on a life of its own and pursued a deeply reductionist agenda, one that became focused to a large extent on myosin II and regulation of the acto-myosin cycling rate. The study of airway biology pursued a reductionist agenda as well, but one that became focused less and less on contractile functions of muscle and instead emphasized immune responses, inflammatory cells and mediators, and, to the extent that smooth muscle remained of interest, that interest centered mainly on synthetic, proliferative and migratory functions [2-7]. Inflammatory remodeling of the airway wall was also recognized as being a key event in the asthmatic diathesis [7-17]. Com- putational models of ever increasing sophistication were formulated in order to better understand the impact of inflammatory remodeling processes upon ASM shortening and acute airway narrowing but, remarkably, the muscle compartment of these models remained at a relatively primitive level, being represented by nothing more than the classical relationship of active isometric force $v$ s. muscle length $[13,16,18-22]$. As discussed below, this description is now considered to be problematic because the very existence of a well-defined static force-length relationship has of late been called into question, as has the classical notion that the muscle possesses a well-defined optimal length. Rather, other factors intrinsic to the muscle, especially muscle dynamics and mechanical plasticity, as well as unanticipated interactions between the muscle and its load, are now understood to be major factors affecting the ability of the muscle to narrow the airway [1,23-27]. 
The topics addressed in this review are intended to highlight recent discoveries that bring airway biology and smooth muscle biophysics into the same arena once again. The emphasis is biophysical properties of airway smooth muscle as they relate to excessive airway narrowing. This is appropriate because, in the end, if airway inflammation didn't cause airway narrowing, then asthma might be a tolerable disease (Julian Solway, personal communication). But asthma is not a tolerable disease. In order to understand the multifaceted problem of bronchospasm in asthma, therefore, an integrative understanding that brings together a diversity of factors will be essential.

\section{Airway hyperresponsiveness}

It was recognized quite early that the lung is an irritable organ and that stimulation of its contractile machinery in an animal with an open chest can cause an increase in lung recoil, air to be expelled, a rise in intratracheal pressure, and an increase in airways resistance [28-31]. However, until the second half of the last century airway smooth muscle was not regarded as being a tissue of any particular significance in respiration mechanics [28]. A notable exception in that regard was Salter [32], who, in 1859 , was well aware of the existence of airway smooth muscle and its potential role in asthma. Airway smooth muscle was first described in 1804 by Reisseisen (as related by Otis [28]) and its functional properties first considered by Einthoven [33] and Dixon and Brodie [31]. More recent studies have shown that the fraction of the tissue volume that is attributable to contractile machinery is comparable for airways, alveolated ducts and blood vessels in the lung parenchyma [34]; the lung parenchyma, like the airway, is a contractile tissue [35-39]. Airway smooth muscle is now recognized as being the major endeffector of acute airway narrowing in asthma [18,21]. There is widespread agreement that shortening of airway smooth muscle is the proximal cause of excessive airway narrowing during an asthmatic attack [17], with swelling of airway wall compartments and plugging by airway liquid or mucous being important amplifying factors $[18,40]$. It remains unclear, however, why in asthma the muscle can shorten excessively.

Airway hyperresponsiveness is the term used to describe airways that narrow too easily and too much in response to challenge with nonspecific contractile agonists [41]. Typically, a graph of airways resistance vs. dose is sigmoid in shape (Fig. 1); the response shows a plateau at high levels of contractile stimulus. Generally, the existence of the plateau is interpreted to mean that the airway smooth muscle is activated maximally and, therefore, has shortened as much as it can against a given elastic load. Once on the plateau, therefore, any further increase in stimulus can produce no additional active force, muscle shortening, or airway resistance.

To say that airways narrow too easily, then, means that the graph of airways resistance vs. dose of a non-specific contractile stimulus is shifted to the left along the dose axis, and that airways respond appreciably to levels of stimulus at which the healthy individual would be unresponsive; this phenomenon is called hypersensitivity. By contrast, to say that the airways narrow too much means that the level of the plateau response is elevated, or that the plateau is abolished altogether, regardless of the position of the curve along the dose-axis; this phenomenon is called hyperreactivity. As distinct from hypersensitivity, it is this ability of the airways to narrow excessively, with an elevated or abolished plateau, that accounts for the morbidity and mortality associated with asthma [42].

It has long been thought that the factors that cause hypersensitivity $v s$. hyperreactivity are distinct, with the former being associated with receptor complement and downstream signaling events but the latter being associated with purely mechanical factors, including the contractile apparatus, the cytoskeleton, and the mechanical load against which the muscle shortens [16,18,21,43]. Macklem has pointed out that once the muscle has become maximally activated it is the active force and the load that become all important, and the plateau response becomes essentially uncoupled from underlying biochemistry, signaling and cell biology [20-22]. As described below, there is reason to think that these distinctions may not be as clear as once believed, however.

Although asthma is usually defined as being an inflammatory disease, the link between the immunological phenotype and the resulting mechanical phenotype associated with disease presentation, including airways hyperresponsiveness, remains unclear; indeed, it is now established that airway hyperresponsiveness can be uncoupled from airway inflammation [44-47]. It remains equally unclear if airway hyperresponsiveness is due to fundamental changes within the smooth muscle itself, as might be caused by inflammatory mediators, chemokines and cytokines [48], or due to changes external to the muscle such as a reduced mechanical load against which the smooth muscle contracts. Still another possibility supported by recent evidence is that there is an interaction of the two wherein the contractile machinery within the smooth muscle cell adapts in response to a change in its mechanical microenvironment $[1,17,24,25,27,49,50]$. Moreover, Tschumperlin and colleagues $[51,52]$ have provided evidence to suggest that bronchospasm can lead to mechanically-transduced pro-inflammatory signaling events in the airway epithelium, in which case 


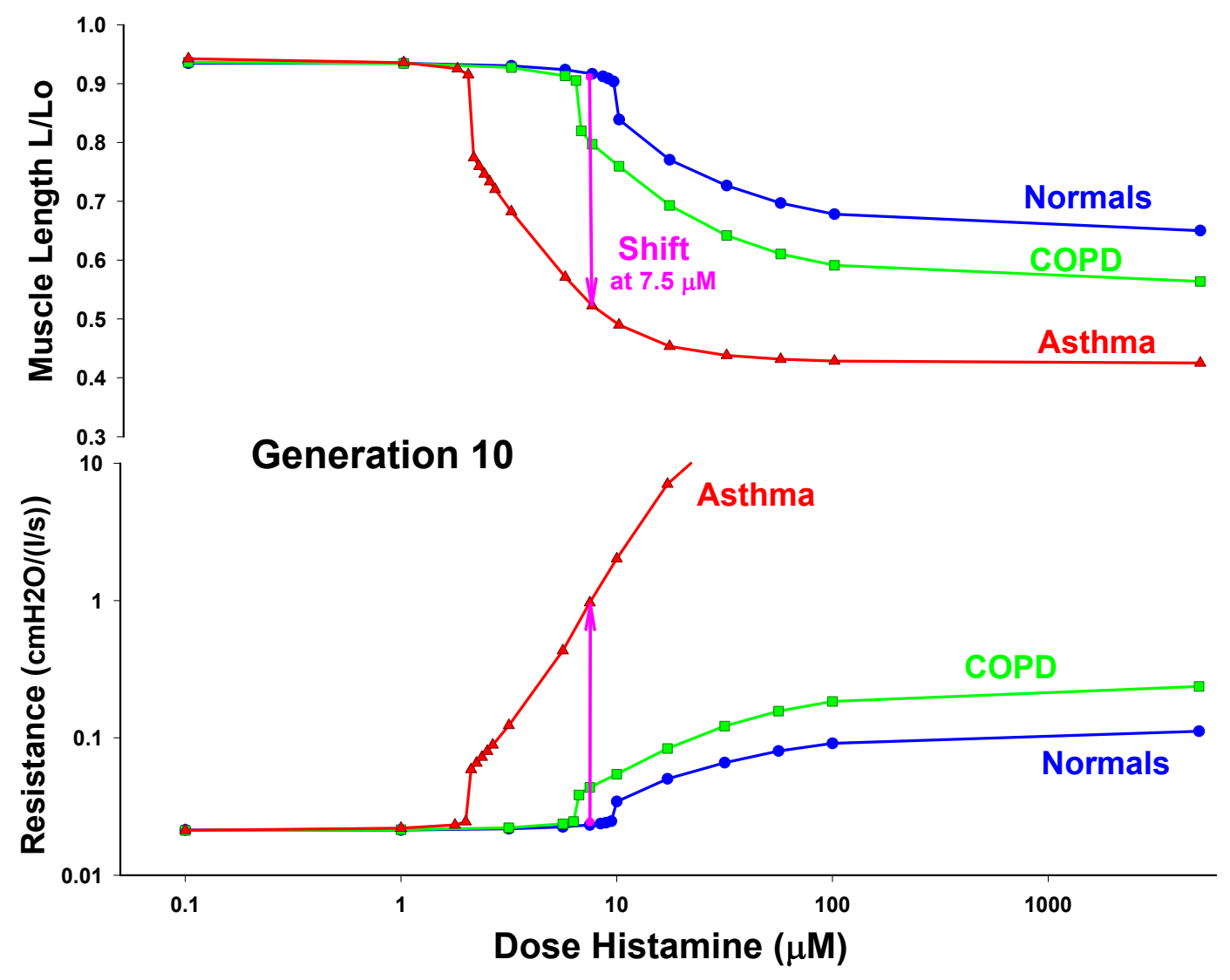

Figure I

A computational result showing airway length (top) and airway resistance (bottom) as a function of agonist concentration for a tenth generation airway [I5I]. The cases shown depict airways from a normal, an asthmatic and a COPD lung. In this computation, the effects of tidal breathing and deep inspirations (6/minute) upon myosin binding dynamics are taken into account explicitly [I5I]. As explained in the text, such an airway exhibits both hyperreactivity and hypersensitivity.

inflammation may cause bronchospasm, but bronchospasm in turn may amplify or even cause inflammation.

In the balance of this review I address the classical picture of smooth muscle behavior and then go on to describe what we know about non-classical behavior in a dynamic mechanical environment driven by the tidal action of breathing. In addition, in recent years we have come to learn that the mechanical environment leads to interesting airway instabilities and adaptation in the muscle itself. Finally, I conclude by providing an emerging integrative context that seems to account for many of these properties that are not accounted for in classical perspectives of smooth muscle biophysics. I do not address the increasing evidence that now suggests that cytokines such as IL-1 $\beta$ and TNF $\alpha$ augment responses to bronchoconstrictor agonists while attenuating the bronchodilation that can be effected by hormones and paracrine agents like epinephrine and $\mathrm{PGE}_{2}$ [53]. Such cytokines, along with growth factors and other inflammatory mediators also result in smooth muscle hyperplasia, at least in culture systems [5]. In culture, extracellular matrix proteins also influence the contractile phenotype of airway smooth muscle cells $[54,55]$. Whether asthmatic inflammation can result in a hypercontractile phenotype remains to be established. 


\section{Classical behavior of airway smooth muscle and the balance of static forces}

The microstructure of striated muscle is highly ordered whereas there is abundant evidence in the literature demonstrating that the cytoskeletal matrix of smooth muscle is quite disordered [56,57]; it is, after all, its amorphous structure that gives 'smooth' muscle its name. Moreover, the cytoskeletal matrix of airway smooth muscle is in a continuous state of remodeling, a point to which we return below. Despite these differences, it has been widely presumed that to a first approximation Huxley's sliding filament model of muscle contraction [58] describes the function of both smooth and striated muscle [59-61]. For many of the biophysical phenomena observed in airway smooth muscle, such as active force generation and shortening velocity, Huxley's model represents a useful tool for thought [61], while for others, like mechanical plasticity, it does not.

As in the case of striated muscle contraction, the principal biophysical parameters that characterize the case of smooth muscle contraction include the maximum active isometric force (or stress, which is simply the force carried per unit area), the length at which the muscle can attain that maximal force (i.e., the optimum length, Lo), and the shortening capacity of the muscle. The sliding filament model of Huxley is the starting point for understanding each of these phenomena. As described by Huxley [58], isometric force, as well as muscle stiffness, are proportional to the number of acto-myosin cross links per unit volume. This is true because, assuming rigid filaments, all bridges within a given contractile unit must act mechanically in parallel, with their displacements being identical and their forces being additive. The maximum active stress supported by smooth $v$ s. striated muscle is approximately the same and is of the order $10^{5}$ Pascal. In striated muscle, the optimum length is attributed to the extent of overlap between the myosin filament and the actin filament, with optimum length corresponding to a maximum number of myosin heads finding themselves within striking distance of an available actin binding site, and the maximum capacity of the muscle to shorten being limited by the collision of the myosin filament end with the z-disc. Smooth muscle possesses no structure comparable to the z-disc, however, although actin filaments terminate in dense bodies, which might come into play in limiting muscle shortening. Whereas unloaded striated muscle can shorten perhaps $20 \%$ from its optimum length, unloaded smooth muscle can shorten as much as 70\% [62-65]. Several physical factors may come into play to limit the capacity for unloaded shortening of smooth muscle. Small $[56,57]$ has shown that the actin filaments of the contractile apparatus connect to the cytoskeleton at cytoplasmic dense bodies and with the longitudinal rib-like arrays of dense plaques of the membrane skeleton that couple to the extracellular matrix. Moreover, the sidepolar configuration of the myosin filament $[66,67]$ is likely to be involved. Still other factors coming into play include length-dependent activation $[68,69]$, lengthdependent rearrangements of the cytoskeleton and contractile machinery $[27,70]$, and length-dependent internal loads $[65,71,72]$.

What are the extramuscular factors that act to limit airway smooth muscle shortening? The basic notion, of course, is that muscle shortening stops when the total force generated by the muscle comes into a static balance with the load against which the muscle has shortened, both of which vary with muscle length. The factors setting the load include the elasticity of the airway wall, elastic tethering forces conferred by the surrounding lung parenchyma, active tethering forces conferred by contractile cells in the lung parenchyma $[73,74]$, mechanical coupling of the airway to the parenchyma by the peribronchial adventitia, and buckling of the airway epithelium and submucosa [75-77]. In addition, the airway smooth muscle itself is a syncytium comprised mostly of smooth muscle cells, aligned roughly along the axis of muscle shortening, and held together by an intercellular connective tissue network. In order to conserve volume, as the muscle shortens it must also thicken. And as the muscle shortens and thickens, the intercellular connective tissue network must distort accordingly. Meiss has shown evidence to suggest that at the extremes of muscle shortening it may be the loads associated with radial expansion (relative to the axis of muscle shortening) of the intercellular connective tissue network that limits the ability of the muscle to shorten further [78].

In the healthy intact dog, airway smooth muscle possesses sufficient force generating capacity to close all airways $[79,80]$. This fact may at first seem to be unremarkable, but it is not easily reconciled with the observation that when healthy animals or humans are challenged with inhaled contractile agonists in concentrations thought to be sufficient to activate the muscle maximally, resulting airway narrowing is limited in extent, and that limit falls far short of airway closure [81,82]. Breathing remains unaccountably easy. Indeed, it is this lightness of breathing in the healthy challenged lung, rather than the labored breathing that is characteristic of the asthmatic lung, that in many ways presents the greater challenge to our understanding of the determinants of acute airway narrowing [83]. Brown and Mitzner [79] have suggested that the plateau of the dose-response curve reflects uneven or limited aerosol delivery to the airways. Another possibility, however, is that mechanisms exist that act to limit the extent of muscle shortening in the healthy breathing lung, whereas these mechanisms become compromised in the asthmatic lung. It has been suspected that the impairment 
of that salutary mechanism, if it could only be understood, might help to unlock some of the secrets surrounding excessive airway narrowing in asthma, as well as the morbidity and mortality associated with that disease [8487]. This brings us to muscle dynamics, deep inspirations, and the potent effects of a time-varying muscle load associated with the act of breathing.

\section{Shortening velocity and other manifestations of muscle dynamics}

The oldest and certainly the simplest explanation of airway hyperreactivity would be that muscle from the asthmatic airway is stronger than muscle from the healthy airway, but evidence in support of that hypothesis remains equivocal $[3,4,88]$. Indeed, studies from the laboratory of Stephens and colleagues [26,89-91] have emphasized that the force generation capacity of allergensensitized airway smooth muscle of the dog, or asthmatic muscle from the human, is no different from that of control muscle. As a result, the search for an explanation turned to other factors, and several alternative hypotheses have been advanced. These fall into three broad classes, each of which is consistent with remodeling events induced by the inflammatory microenvironment, and include an increase of muscle mass $[13,77,92]$, a decrease of the static load against which the muscle shortens $[13,75,77,92]$, and a decrease of the fluctuating load that perturbs myosin binding during breathing, described in greater detail below $[23,24,93,94]$. Aside from their effects on acto-myosin binding, changes in the static load and/or the dynamic load also lead to dramatic cytoskeletal remodeling events as the smooth muscle cell adapts to its microenvironment. Together, these hypotheses are attractive because they suggest a variety of mechanisms by which airway smooth muscle can shorten excessively even while the isometric force generating capacity of the muscle remains essentially unchanged.

\section{Setting the muscle length: a process equilibrated statically or dynamically?}

Even if the force generating capacity is unchanged, a consistent association has been noted between airway hyperresponsiveness and unloaded shortening velocity of the muscle $[89,90,95-97]$. This association suggests the possibility that the problem with airway smooth muscle in asthma may be that it is too fast rather than too strong. But how shortening velocity - a dynamic property of the muscle - might cause excessive airway narrowing - a parameter that was thought to be determined by a balance of static forces - remains unclear. To account for increased shortening capacity of unloaded cells, Stephens and colleagues have reasoned that upon activation virtually all muscle shortening is completed within the first few seconds [97]. As such, the faster the muscle can shorten within this limited time window, the more it will shorten.
However, in isotonic loading conditions at physiological levels of load, muscle shortening is indeed most rapid at the very beginning of the contraction, but appreciable shortening continues for at least $10 \mathrm{~min}$ after the onset of the contractile stimulus [24]. An alternative hypothesis to explain why intrinsically faster muscle might shorten more comes from consideration of the temporal fluctuations of the muscle load that are attributable to the action of spontaneous breathing $[24,88,98]\}$. Load fluctuations that are attendant to spontaneous breathing are the most potent of all known bronchodilating agencies $[99,100]$. Among many possible effects, these load fluctuations perturb the binding of myosin to actin, causing the myosin head to detach from actin much sooner than it would have during an isometric contraction. But the faster the myosin cycling (i.e., the faster the muscle), the more difficult it is for imposed load fluctuations to perturb the actomyosin reaction. This is because the faster the intrinsic rate of cycling, the faster will a bridge, once becoming detached, reattach and contribute once again to active force and stiffness.

Why is muscle from the allergen sensitized animal or asthmatic subject faster? For technical reasons, in their study on biopsy specimens from asthmatic subjects Ma et al [97] did not measure expression of myosin light chain kinase, but their finding of increased content of message strongly implicates MLCK. Although regulation of myosin phosphorylation is a complex process with multiple kinase and phosphatase pathways, this finding substantially narrows the search for the culprit that may account for the mechanical changes observed in these cells. Also, these studies seem to rule out changes in the distribution of myosin heavy chain isoforms; content and isoform distributions of message from asthmatic cells showed the presence of smooth muscle myosin heavy chain A (SM-A) but not SM-B, the latter of which contains a seven-amino acid insert, is typical of phasic rather than tonic smooth muscle, and is by far the faster of the two isoforms [101,102]. Together, these findings confirm in muscle biopsy specimens from the asthmatic airway a number of findings from the allergen-sensitized dog model.

\section{Cycling rate regulation}

In smooth muscle, shortening velocity and its determinants are of particular interest [60,103]. Compared to striated muscle, the maximum unloaded shortening velocity of smooth muscle is smaller by more than an order of magnitude. This difference seems to be a adaptation to smooth muscle functions; whereas striated muscles typically produce motion or work in an efficient manner (i.e., converting chemical energy into mechanical energy with a small amount of energy lost to heat), smooth muscles are found in hollow organs where they serve to maintain tone or shape in an economical manner (i.e., doing so at a rate 
of chemical energy utilization that is smaller than that consumed striated muscle by about 300 fold $[59,60]$. Since the rate of myosin ATPase activity is tied directly to the myosin cyclic rate $[104,105]$, a slower cycling rate implies economical maintenance of tone.

If smooth muscle is activated but held isometrically as the waiting time between the stimulus onset and a subsequent quick release is increased, the isometric force grows but the rate of ATP utilization and unloaded shortening velocity immediately after the release progressively decrease; this curious behavior represents a major distinction between smooth and striated muscle. Huxley's view of muscle contraction implies that the unloaded shortening velocity is set by the rate at which the myosin head can advance along the actin filament. Accordingly, for a given myosin step size, this means that shortening velocity is a direct measure of cross bridge cycling rate. Since the shortening velocity is found to decrease appreciably with increasing waiting time, the logical explanation following these ideas is that the cycling rate is a regulated variable and decreases as a function of time since the onset of the activation. Taken together, force maintenance, down-regulation of unloaded shortening velocity, and reduced rates of ATP utilization, comprise what is known as the latch state, or, equivalently, the latch phenomenon.

\section{Latch}

Force generated by any smooth muscle is sustained by cyclic interactions of myosin with actin. With onset of the contractile event, myosin-actin cycling begins and the number of interactions (bridges) increases and eventually approaches a steady state. It is widely agreed that during this process the rate of bridge cycling initially increases but then becomes substantially diminished. The mechanisms of cycling rate regulation remain very much an open question in the literature [103,106-113].

Among mechanisms of cycling rate regulation that have been proposed, the foremost is the latch hypothesis of Hai and Murphy, which has the attributes of being the simplest and capturing the central importance of phosphorylation of the $20 \mathrm{kDa}$ myosin regulatory light chain [103,106,114-116]. Murphy and his colleagues suggested that the latch phenomenon arises as rapidly cycling cross bridges are replaced progressively by slowly cycling latch bridges if given enough time at a fixed muscle length, where the latch bridge is nothing more than a myosin head whose $20 \mathrm{kDa}$ regulatory light chain becomes dephosphorylated while remaining attached to actin and maintaining both force and stiffness. The central notion is that the latch bridge has a very small rate of detachment from actin and, as a result, the latch bridge comprises an internal load against which rapidly cycling bridges must shorten [61].
Within the latch schema, the attainment of the isometric steady state implies that the population distribution of myosin molecules among their four possible states (attached vs. unattached to actin, phosphorylated vs. unphosphorylated regulatory light chains) have come to a binding equilibrium set by a balance of kinetic rate processes, many of which are ATP dependent. Once enough time has passed that this balance is attained and myosin has come to a binding equilibrium appropriate to isometric steady-state conditions, the muscle is then said to be in the latch state. Thus, the latch state corresponds to what I will refer to as a static equilibrium of myosin binding at the molecular level, and a balance of static forces at the mechanical level.

Whether the latch bridge might account for the latch phenomenon remains a point of some contention, however. The accessory proteins calponin and caldesmon are known to modulate the rate of muscle shortening, and have been suggested as being molecules responsible for or contributing to the latch phenomenon, but the mechanisms of action of these molecules are not well understood [108,117-119]. Finally, if contractile units were evanescent and the number of such units in series were to decrease progressively during a contractile event, as discussed below, it has been suggested that these adaptations might account for the latch phenomenon [25].

\section{Non-classical behavior: load fluctuations and dynamic equilibration of the muscle length}

Load fluctuations are imposed continuously on airway smooth muscle and pulmonary vascular smooth muscle by the tidal action of breathing, and on muscular systemic arteries and arterioles by the pulsatile action of blood ejected from the heart. Smooth muscles in the urethra, urinary bladder, and gut are also subjected to periodic stretch. Accordingly, imposed fluctuations in muscle load seem to be a universal part of smooth muscle physiology.

It is well established that imposition of load fluctuations on smooth muscle inhibits development of active force and stiffness $[80,98,120]$. Although imposed load fluctuations induce important plastic changes in the cytoskeleton, as described later in this review $[27,70]$, a major part of the force and stiffness inhibitions that are observed are attributable to direct effects of tidal stretch upon bridge dynamics $[24,61,98]$.

\section{Perturbed equilibria of myosin binding}

In the case of airway smooth muscle, the effects of oscillatory loading were first addressed by Sasaki and Hoppin and later by Gunst and colleagues, who demonstrated that imposition of tidal changes in muscle length depresses active force $[98,120-123]$. Subsequent studies $[24,98]$ showed that imposed fluctuations of muscle length about 
a fixed mean length cause depression of muscle force and muscle stiffness (averaged over the stretch cycle); imposed length fluctuations also cause augmentation of the specific rate of ATP utilization and the hysteresivity (related to the muscle viscosity and an index of bridge cycling rate, as described below [105]. Thus, from both a mechanical and a metabolic point of view, the perturbed state is a hot or a melted state of the muscle [23,24,61,94]. Imposed force fluctuations about a fixed mean distending force systematically bias the airway smooth muscle toward lengthening; this phenomenon is called fluctuation-driven muscle lengthening [24]. Although tidal stretches smaller than $1 \%$ of muscle length produce only trivial mechanical effects, tidal stretches in the range of amplitudes expected during quiet tidal breathing (about 3\% of muscle length) produce force inhibition that is equipotent with concentrations of isoproterenol in the range $10^{-7}$ to $10^{-5} \mathrm{M}$ [99]. Molfino et al. showed in humans that brief cessation of tidal breathing causes the cross-sectional area of central airways to decrease by about half under the influence of baseline smooth muscle tone, and when tidal breathing is resumed the airway promptly dilates [124]. Taken together, these findings suggest that quiet tidal breathing is as effective in relaxing airway smooth muscle as is a potent relaxing agonist.

Importantly, there is increasing evidence that the potent bronchodilating response to periodic stretch and deep inspirations is impaired in asthma, and that this impairment may be the proximal cause of the loss of the plateau of the dose-response curve and the resulting morbidity of the disease $[81,84,86,87,125,126]$. There exists also a bronchoprotective effect of deep inspirations; deep inspirations prior to agonist challenge have been shown to blunt the subsequent contractile response [127-131]. It has been suggested that the bronchoprotective effect of deep inspirations are even more important than the bronchodilating response, and it too is profoundly impaired in asthma.

Lung inflations strain airway smooth muscle with each breath, and these periodic mechanical strains are transmitted to the myosin head and cause it to detach from the actin filament much sooner than it would have in isometric circumstances. This premature detachment profoundly reduces the duty cycle of myosin, typically by as much as $50-80 \%$ of its unperturbed isometric steady-state value, and depresses total numbers of bridges attached and active force to a similar extent. Of the full isometric force generating capacity of the muscle, therefore, only a small fraction ever comes to bear on the airway during tidal breathing, even when the muscle is activated maximally. Since bridge cycling is strongly perturbed by the imposed tidal stretches over time the number of myosin attachment and detachment events come into a dynamic bal- ance. To distinguish it from the state that prevails in static loading conditions, this state has been called a perturbed equilibrium of myosin binding [24,61].

In pathological circumstances the tidal strains acting on myosin can become compromised, however. For example, in the chronically inflamed airway the peribronchial adventitia thickens $[8,9,132]$; this thickening decreases tidal muscle strains and thereby permits myosin binding to approach an unperturbed binding equilibrium. In doing so, the muscle would then generate the full complement of isometric force appropriate to the stimulus. Any factor that lessens peribronchial stress will decrease the force fluctuations impinging upon the muscle, including inflammatory thickening of the lamina reticulosa, thickening of the peribronchial adventitia, loss of lung elastic recoil, breathing at low lung volumes, and failure to take deep breaths $[18,21,22,75,133-135]$; in addition, Colebatch and colleagues found evidence of increased rigidity of airways in asthmatic subjects [136]. If any of these factors pertain, then the perturbed equilibrium of myosin binding can collapse toward a static binding equilibrium. For example, if for any reason the muscle should stretch a bit less, then fewer bridges would be perturbed. Because more attached bridges working in parallel are harder to break than fewer, the muscle would then become stiffer still and therefore stretch even less, and so on. Ultimately this process reaches the limit in which the muscle may become so stiff that the physiological forces acting on it are insufficient to stretch the muscle appreciably, leaving the muscle stuck at its static equilibrium length $[23,24,61]$. Compared with the perturbed state, this statically equilibrated contractile state is also characterized by slow bridge cycling and a small rate of ATP utilization per bridge attached or per unit force developed [24]. So from both the mechanical and the metabolic point of view, it would appear to be a cold or 'frozen' contractile state. The muscle could be said to be statically equilibrated and frozen in the latch state.

This point of view leads to the hypothesis that airway hyperresponsiveness is associated with the failure of the underlying perturbed binding equilibrium to sustain itself, and an ensuing collapse of myosin binding kinetics to the binding equilibrium that pertains in static conditions and latch [23]. Clearly, this constellation of factors points towards dynamic instability, as described below.

\section{Dynamic muscle instabilities}

It is a well-established empirical fact that within any given lung or lung segment the response of airways to contractile agonists is always accompanied by 1) extreme heterogeneity of the response and 2) sensitivity of the response to the amplitude of the tidal volume and the magnitude of the load fluctuation [36,100,137-142]. It has been 
speculated that the observation of a smoothly graded decline of tests of lung functions (such as lung resistance) with progressively increasing doses of contractile agonist might be better explained by progressive changes in number of open airways accommodating gas flow rather than by some smoothly changing reduction in the airway caliber of each [138]. Indeed, the heterogeneity of the response is so extensive that peripheral airways have sometimes been thought of as being partitioned into only two quantum-like states, as it were, either open wide or almost closed entirely, with virtually no intermediate state $[138,143,144]$. Several plausible factors have been invoked to try to account for this profound heterogeneity of the contractile response, including intrinsic inhomogeneities in airway structure, muscle amounts, muscle sensitivity to agonist, and nonuniformity of agonist delivery $[36,79,145]$.

Anafi and Wilson considered the narrowing of an airway containing activated airway smooth muscle subject to load fluctuations as would occur during breathing $[146,147]$. Their mathematical analysis shows that in some circumstances such an airway must become unstable. Of course, the generic idea that airways can be unstable is not at all new [148], but the analysis of Anafi and Wilson identified a new class of airway instability that is intrinsically dynamic and, in particular, is rooted in the response of airway smooth muscle to imposed load fluctuations.

To appreciate the potential importance of this muscle instability, we imagine a lung in which there are a large number of airways that are all operating in parallel and that are in every regard identical. The airway smooth muscle is activated uniformly and subjected to identical load fluctuations caused by the tidal action of breathing. Even though inter-regional differences are infinitesimally small at the outset, any small perturbation would be amplified by the processes described above. And as the differences grow the amplification grows. When the process eventually becomes dynamically equilibrated, the airways will be seen to have partitioned themselves between only two states in order to accommodate the total flow-one state effectively wide open and the other nearly closed. The analysis of Anafi and Wilson and that of Fredberg and colleagues [24] address overlapping but different aspects of airway narrowing; although the relationship between these perspectives remains somewhat unclear, airway smooth muscle in the closed airways might be expected to correspond to the static or 'frozen' state, and muscle in the open airways might be expected to correspond to a 'melted' state with an underlying perturbed equilibrium of myosin binding. Changes in tidal volume would affect the number of airways in each state.
In the healthy lung during spontaneous breathing, tidal volume and associated force fluctuations acting on airway smooth muscle may be large enough to keep almost all units in the open/melted state and out of jeopardy of closure. But if tidal volumes were compromised, or deep inspirations were prohibited, or transmission of force fluctuations to the airway smooth muscle were to become compromised, then a larger fraction of units would be expected to be found in the closed/frozen state. Therefore, this picture would seem to be able to explain in one stroke both a profound heterogeneity of the airway response and its sensitivity to tidal volume.

This insight on instability of smooth muscle dynamics does not preclude important contributions from intrinsic heterogeneities that exist amongst airways, of course. The Anafi-Wilson instability is attractive, though, because it shows that it is not necessary to postulate intrinsic airway heterogeneity of any kind in order to account for both a profound heterogeneity of the airway response and its sensitivity to tidal volume.

\section{Deep Inspirations}

Jensen and colleagues [149] followed the earlier studies of Fish [84], Lim et al. [86], and then Skloot [87] to show in normal individuals challenged with nonspecific contractile agonists that a single deep inspiration (DI) causes a prompt and dramatic decrease in airway resistance (Raw) followed by a slow return of Raw to the level observed prior to the DI. By contrast, in individuals with severe asthma a single DI causes a prompt but only modest decrease in Raw followed by rapid return of Raw to the level observed prior to the DI. The findings in challenged normal individuals are consistent with disruption of cross bridges as described above. In the asthmatic, however, it is plausible that bridges were stretched, but not enough to disrupt an appreciable fraction of the acto-myosin bonds. Immediately following the deep inspiration, the rapid recovery of Raw to pre-DI levels could reflect either a rapid elastic recoil of the stretched muscle, or an altered cytoskeletal remodeling response to the DI (described below), or reattachment of bridges that were disrupted, but at a rate that is faster than that observed in healthy individuals.

The crucial role of tidal loading of the ASM was further demonstrated by Mitzner and Brown in an ingenious use of high resolution CT in a dog model in which one lung was ventilated while the other was held isovolumic [150]. Compared to the lung undergoing cyclic volume changes, the isovolumic hung was found to be both hyperresponsive and refractory to the bronchodilating effects of a subsequent deep inspiration. 
In order to better understand these processes and, especially, the impact of inflammatory remodeling processes upon ASM shortening and acute airway narrowing, Mijailovich and colleagues [151] developed a computational model which, unlike previous attempts $[13,16,21]$, took into account explicitly molecular dynamics of myosin and the ability of load fluctuations associated with tidal breathing and periodic deep inspirations to perturb myosin binding. Results for a generation 10 airway reveal hyperreactive airways in asthma and COPD, as was found by others using static muscle models (Fig. 1). However, this model of molecular dynamics expresses two additional phenomena that the static model does not. The first is induction of hypersensitivity - a shift of the doseresponse curve to the left - which arises from myosin binding dynamics and their interaction with a fluctuating load. As noted above, mechanisms responsible for hypersensitivity $v s$. hyperreactivity had been though to be distinct whereas, by contrast, this result shows that myosin binding dynamics in the setting of a fluctuating mechanical load can elicit both. Compared to the case of the asthmatic airway, in the case of the normal airway the action of tidal loading upon myosin binding dynamics is sufficient to inhibit airway narrowing until the level of muscle activation is relatively large. The second phenomenon is what would appear to be a discontinuous or unstable response: with an increasing degree of muscle activation (agonist dose) there arises a value beyond which, when the airway does begin to narrow, it does so precipitously.

Taken together, these non-classical behaviors support the notion that activated airway smooth muscle is typically melted by the tidal action of breathing and, therefore, muscle length is dynamically equilibrated. Nonetheless, in pathological circumstances, as described below, muscle can become frozen in the latch state.

\section{Clinical manifestations}

In practical terms, specific instances in which elevated rates of bridge cycling might come into play include the differences in airway responsiveness that have been observed between normal versus allergen sensitized muscle, between certain animal strains and, in some species, between mature versus immature animals [68,142,152156]. This rationale leads us to a plausible mechanism by which the rate of bridge cycling and its regulation may be reasonably thought to bear upon the prevalence of childhood asthma and its changes with lung maturation and allergic status.

Although far from explaining these phenomena in their entirety, the perturbed equilibrium hypothesis may help to tie together still other loose ends (Fig. 2). According to that hypothesis, greater contractile responses are favored whenever the force fluctuations acting on the airway become compromised, not only when the peribronchial adventitia undergoes cytokine-driven inflammatory thickening, but also when the lung loses elastic recoil, or tidal lung expansion becomes diminished. These instances bring immediately to mind not only asthma, but also emphysema, normative aging, restrictive disorders of the chest wall, obesity, and cervical spinal cord injury, each of which is known to be associated with a predisposition for airway hyperresponsiveness or asthma [157-163]. Reduced amplitude of force fluctuations may come into play similarly in asthma exacerbations that occur during sleep (nocturnal asthma) [164,165] and during late pregnancy $[166,167]$ where, in both circumstances, functional residual capacities are diminished [168,169], suggesting in turn diminished lung recoil and smaller load fluctuations acting upon the airway smooth muscle [24,94]. Moreover, it is clear that when inflammatory remodeling of the airway does occur, the perturbed equilibrium hypothesis predicts that the resulting predisposition for airway hyperresponsiveness might persist long after the inflammation itself is resolved $[46,170]$. And finally, perturbed equilibria might also help to explain why the obstructive response in exercise-induced asthma typically begins only after cessation of the exercise, when tidal volumes have declined to resting levels.

\section{Mechanical plasticity: another non-classical feature of airway smooth muscle}

When activated muscle in the muscle bath is subjected to progressively increasing load fluctuations approaching the magnitude and frequency expected during normal breathing, the muscle lengthens appreciably in response [24]. But when load fluctuations are progressively reduced, the muscle reshortens somewhat but fails to return to its original length. Incomplete reshortening after exposure to tidal loading is not accounted for by muscle injury; the original operating length can be recovered simply by removing the contractile agonist and allowing the muscle a short interval before recontracting. Neither can incomplete reshortening be accounted for by myosin dynamics; myosin dynamics by themselves predict complete reshortening when the load fluctuations are removed [24]. Thus, the failure of activated muscle to reshorten completely is evidence of a plasticity of the contractile response. During a sustained contraction, the operational length of the muscle for a given loading, or the force at a given length, can be reset by loading and the history of that loading $[1,24,25,27,49,70,171-174]$. In healthy individuals this plasticity seems to work in a favorable direction, allowing activated muscle to be reset to a longer length. The asthmatic, it has been argued, never manages to melt the contractile domain in the airway smooth muscle and, as such, the benefits of this plastic response are not attained. 


\section{Universe of AHR Phenotypes: factors predisposing for excessive airway narrowing?}

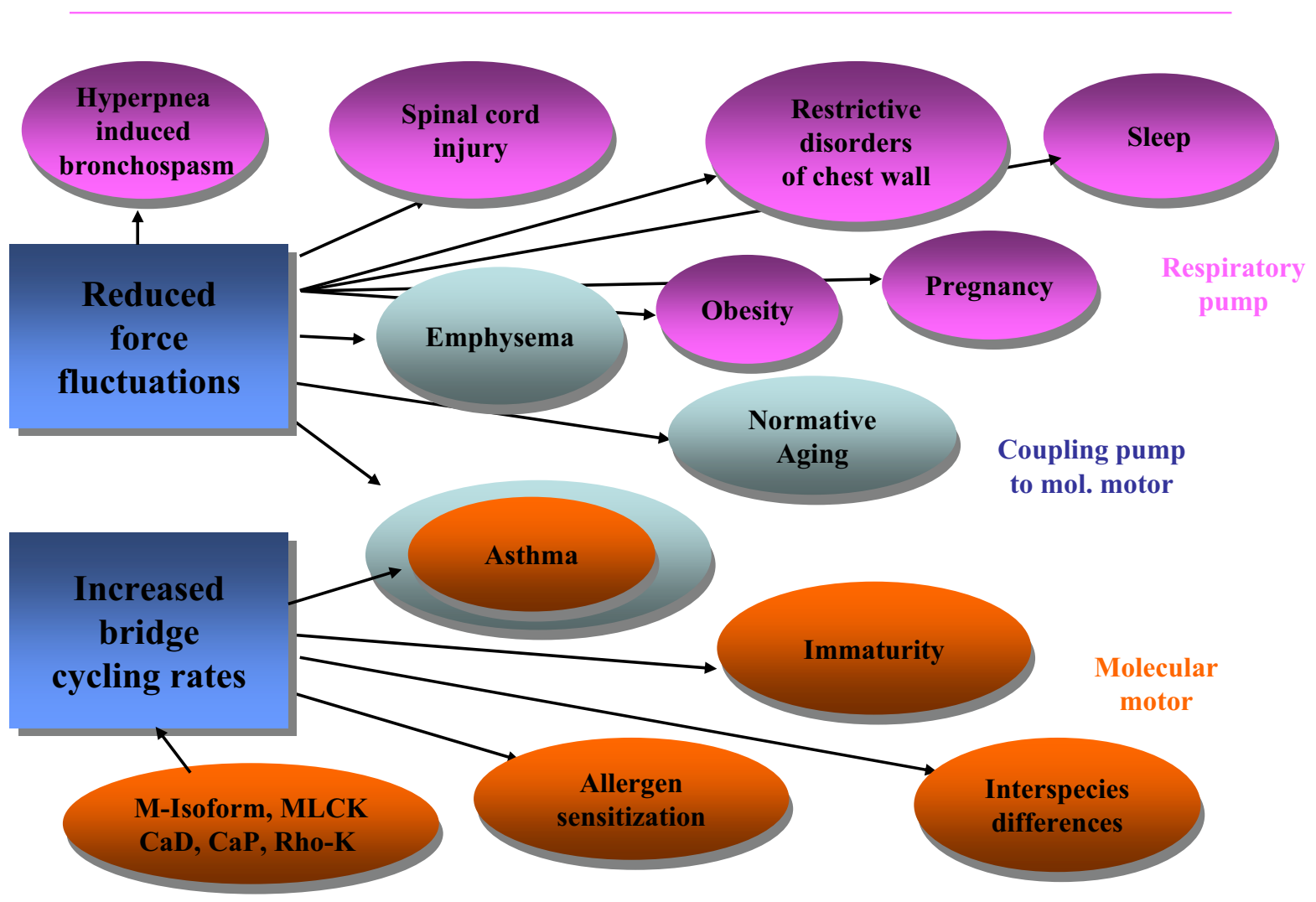

Figure 2

The perturbed equilibrium hypothesis connects phenotypes that were largely unexplained and had been thought to be essentially unrelated. Reduced force fluctuations and/or increased bridge cycling rates allow airway smooth muscle to more nearly approach a static equilibrium of myosin binding (latch) and the frozen state. Airway hyperresponsiveness phenotypes shown in blue correspond to circumstances in which the airway and airway smooth muscle might be normal but there is a problem with the respiratory pump, i.e., the muscles of the chest wall. Those shown purples correspond to phenotypes in which the airway smooth muscle may be normal, but there is a problem in the mechanical coupling between the respiratory pump and the myosin motor. Finally, those shown in green correspond to phenotypes in which the problem may be at the level of the myosin motor itself. At that level, the rate of bridge cycling is thought to be influenced by its isoform, the amount of myosin light chain kinase, caldesmon, calponin, Rho-kinase and other factors.

It is now firmly established that airway smooth muscle can somehow adapt its contractile machinery, as well as the cytoskeletal scaffolding on which that machinery operates, in such a way that the muscle can maintain the same high force over an extraordinary range of muscle length $[1,24,25,27,70,173-178]$; ASM is characterized by its ability to disassemble its contractile apparatus when an appropriate stimulus is given, and its ability to reassemble that apparatus when accommodated at a fixed length.
When exposed to contractile agonists, airway smooth muscle cells in culture reorganize cytoskeletal polymers, especially actin [179], and become stiffer [180]. Although cell stiffening is attributable largely to activation of the contractile machinery, an intact actin lattice has been shown to be necessary but not sufficient to account for the stiffening response [180]. 
Malleability of the cell and its mechanical consequences have been called by various authors mechanical plasticity, remodeling, accommodation or adaptation. Even though the force generating capacity varies little with length in the fully adapted muscle, the unloaded shortening velocity and the muscle compliance vary with muscle length in such a way as to suggest that the muscle cell adapts by adding or subtracting contractile units that are mechanically in series. The mechanisms by which these changes come about and the factors that control the rate of plastic adaptation are unknown, however.

Several hypotheses have been advanced to explain smooth muscle plasticity. Ford and colleagues have suggested that the architecture of the myosin fibers themselves may change [27], while Gunst and colleagues have argued that it is the connection of the actin filament to the focal adhesion plaque at the cell boundary that is influenced by loading history [70,171,172]. Alternatively, another notion is that secondary but important molecules stabilize the cytoskeleton, and as the contractile domain melts under the influence of imposed load fluctuations, those loads must be borne increasingly by the scaffolding itself, and thus reflects malleability of the cytoskeletal domain $[23,54,70,181]$. In that connection a role for the Rho-A pathway has been suggested [54,182] and some evidence now suggests that the p38 MAP kinase pathway may be involved [50]. Airway smooth muscle incubated with an inhibitor of the p38 MAP kinase pathway demonstrates a greater degree of fluctuation-driven muscle lengthening than does control muscle, and upon removal of the force fluctuations it remains at a greater length. Moreover, force fluctuations themselves activate the p38 MAP kinase pathway. It is noteworthy in that connection that heat shock protein 27 has been implicated as an essential element in the motility of airway smooth muscle cells and is a downstream target of rho and p38 [118,183187]. These findings are consistent with the hypothesis that stress response pathways may somehow stabilize the airway smooth muscle cytoskeleton and limit the bronchodilating effects of deep inspirations.

Regardless of the specific molecules and mechanisms invoked to explain the plasticity of the contractile response, the melting of the contractile domain would appear to be a necessary (or permissive) event, but one that by itself is not sufficient to explain the effects of the history of tidal loading. This brings us, finally, to the notion of the cytoskeleton acting as a glassy material.

\section{An emerging question: are we built of glass?}

The abilities of the cytoskeleton (CSK) to deform, to flow, and to remodel (i.e., mechanical plasticity) come into play in a wide variety of situations, from cell division, crawling and extravasation to invasion, contraction and wound healing.

Deformation, flow and remodeling of the airway smooth muscle cell can be described at the molecular level by specific modes of molecular motion and interactions between specific molecular species, at least in principle. The straight-forward approach would be to use direct numerical simulation to describe these molecular interactions within an integrated cytoskeletal lattice and then go on to compute the macroscale integrative properties that result. Direct numerical simulation faces three daunting problems, however. The first is shear complexity; the number of cytoskeletal molecular species is counted in the scores. Moreover, integrated multi-molecular assemblies in airway smooth muscle comprise a messy microstructural geometry, one characterized by a degree of long range order that is far less than that observed in ordinary solids but far greater than that found in fluids. The second is that the list of species remains incomplete and the nature of most protein-protein interactions has yet to be characterized biophysically, with the acto-myosin interaction being the exception that proves the rule. And third, there is good evidence to suggest that in several regards these systems exist far away from local thermodynamic equilibrium (LTE); elemental components do not enjoy a fixed spatial address and, instead, are closely packed and continuously jostling one another in a never-ending search for a minimum energy configuration but never managing to find one. Accordingly, these configurations are adaptable, being in a continuous state of remodeling and, in the process, consuming energy on an ongoing basis via the hydrolysis of ATP. If the first two problems are not enough to saturate the most powerful present-day computers, the non-LTE nature of the problem is particularly thorny because it adds a crucial dimension to the biophysics at the same time that it invalidates a major class of computational approaches, namely, those based on principles of energy minimization.

All three problems are addressed by the approach of Fabry et al. $[[187,189]$. Using airway smooth muscle cells in a culture system, Fabry discovered that integrative statistical properties of the cytoskeleton, such as measures of its ability to deform, to flow and to remodel, conform at the macroscale to a universal empirical framework, namely, that of glassy systems. Findings to date suggest that these processes depend mainly on a putative energy level in the cytoskeletal lattice, where that energy is representative of the amount of molecular agitation, or jostling, present in the lattice relative to the depth of energy wells that constrain molecular motions. This energy level can be expressed as an effective lattice temperature - as distinct from the familiar thermodynamic temperature. Even while the thermodynamic temperature is held fixed this 
effective temperature can change, can be manipulated, and can be measured. The higher the effective temperature, the more frequently do elemental structures trapped in one energy well manage to hop out of that well only to fall into another. The hop, therefore, can be thought of as the fundamental molecular remodeling event.

Among the many consequences of these findings, one can easily show that the rate of cytoskeletal remodeling (plastic adaptation) must scale as this effective temperature; when the matrix is "hot", as it is early an a contractile event for example, the rate of remodeling can be fast. But later in the contractile event, as the effective temperature falls and the matrix "cools", the rate of remodeling slows [188-190]. If the effective temperature falls enough that remodeling virtually comes to a standstill, the matrix behaves as if it were frozen. This latter state is consistent with and subsumes the latch state, as described above, while load fluctuations driven by the action of breathing impinge on the cell and represent another source of agitation whose action is consistent with an elevated effective temperature [[187,189]: Gunst, 2003 \#1051]. Taken together, these features describe a soft glass, and the effective temperature at which all remodeling ceases is called the glass transition temperature. Data available to date conform in many ways to predictions based upon the idea of traps and hops, and conform as well to closely similar behavior that is shared by other soft materials found in nature including foams, pastes, slurries, colloids and some clays. Taken together, these are referred to in the literature as the class of soft glassy materials.

\section{Future directions}

It has become well established that muscle length is equilibrated dynamically rather than statically, and that in a dynamic micro-environment non-classical features of muscle biophysics come to the forefront, including unanticipated interactions between the muscle and its timevarying load, as well as the ability of the muscle cell to adapt rapidly to changes in its mechanical microenvironment. Evidence supporting the notion of a highly malleable cell is accumulating rapidly, but a mechanistic basis to explain this malleability is only beginning to emerge. The notion that airway smooth muscle malleability and remodeling might be explained as a reflection of glassy behavior in the neighborhood of a glass transition is attractive because it is rather simple yet seems to tie together diverse behaviors within a unified empirical framework [188-190]. But whether this line of thinking will bear fruit remains to be seen.

\section{References}

I. Seow CY, Fredberg J]: Historical perspective on airway smooth muscle: the saga of a frustrated cell. J Appl Physiol 200I, 91:938-952.
2. Black JL, Johnson PR, Armour CL: Factors controlling transduction signaling and proliferation of airway smooth muscle. Curr Allergy Asthma Rep 200 I, I:I I6-121.

3. Black JL, Johnson PR: What determines asthma phenotype? Is it the interaction between allergy and the smooth muscle? Am J Respir Crit Care Med 2000, 16 1:S207-10.

4. Black JL, Johnson PR: Airway smooth muscle in asthma. Respirology 1996, I:I53-158.

5. Kelleher MD, Abe MK, Chao T.-S. Oliver, Jain M, Green JM, Solway J, Rosner MR, Hershenson MB: Role of MAP kinase activation in bovine tracheal smooth muscle mitogenesis. Am. J. Physiol. 1995, 268:L894-L90I.

6. Amrani $Y$, Panettieri RA: Airway smooth muscle: contraction and beyond. Int J Biochem Cell Biol 2003, 35:272-276.

7. Holgate ST, Peters-Golden M, Panettieri RA, Henderson W. R., Jr.: Roles of cysteinyl leukotrienes in airway inflammation, smooth muscle function, and remodeling. J Allergy Clin Immunol 2003, II I:SI 8-34; discussion S34-6.

8. McParland $\mathrm{BE}$, Macklem PT, Pare PD: Airway wall remodeling: friend or foe? J Appl Physiol 2003, 95:426-434.

9. Wang L, McParland BE, Pare PD: The functional consequences of structural changes in the airways: implications for airway hyperresponsiveness in asthma. Chest 2003, 123:356S-62S.

10. Homer RJ, Elias JA: Consequences of long-term inflammation. Airway remodeling. Clin Chest Med 2000, $21: 331-43$, ix.

II. Zhu Z, Lee CG, Zheng T, Chupp G, Wang J, Homer RJ, Noble PW, Hamid $Q$, Elias JA: Airway inflammation and remodeling in asthma. Lessons from interleukin II and interleukin 13 transgenic mice. Am J Respir Crit Care Med 200I, 164:S67-70.

12. James AL, Pare PD, Hogg JC: The mechanics of airway narrowing in asthma. Am. Rev. Respir. Dis. 1989, 139:242-246.

13. Lambert RK, Wiggs BR, Kuwano K, Hogg JC, Pare PD: Functional significance of increased airway smooth muscle in asthma and COPD. J. Appl. Physiol. 1993, 74:277I-278I.

14. Moreno R, Hogg JC, Paré PD: Mechanics of airway narrowing. Am. Rev. Respir. Dis. 1986, 133:1 I7I-I I80.

15. Paré PD, Wiggs BR, James A, Hogg JC: The comparative mechanics and morphology of airways in asthma and in chronic obstructive pulmonary-disease. Am. Rev. Respir. Dis. 1991, |43: | |89-1193.

16. Wiggs BR, Bosken C, Paré PD, James A, Hogg JC: A model of airway narrowing in asthma and in chronic obstructive pulmonary disease. Am. Rev. Respir. Dis. 1992, I 45: I 25 I-I 258.

17. Dulin NO, Fernandes DJ, Dowell M, Bellam S, McConville J, Lakser O, Mitchell R, Camoretti-Mercado B, Kogut P, Solway J: What evidence implicates airway smooth muscle in the cause of BHR? Clin Rev Allergy Immunol 2003, 24:73-84.

18. Lambert RK, Pare PD: Lung parenchymal shear modulus, airway wall remodeling, and bronchial hyperresponsiveness. J. Appl. Physiol. 1997, 83:140-147.

19. Macklem PT: Mechanical factors determining maximum bronchoconstriction. Eur Respir J 1989, 6:516s-519s.

20. Macklem PT: Bronchial hyperresponsiveness. Chest 1987, 91:189S-191S.

21. Macklem PT: A theoretical analysis of the effect of airway smooth muscle load on airway narrowing. Am. J. Respir. Crit. Care Med. 1996, 153:83-89.

22. Macklem PT: A hypothesis linking bronchial hyperreactivity and airway inflammation: implications for therapy. Annals of Allergy 1990, 64:113-116.

23. Fredberg JJ: Frozen objects: small airways, big breaths, and asthma. J Allergy Clin Immunol 2000, 106:6I5-624.

24. Fredberg JJ, Inouye DS, Mijailovich SM, Butler JP: Perturbed equilibrium of myosin binding in airway smooth muscle and its implications in bronchospasm. American Journal of Respiratory and Critical Care Medicine 1999, I59:I-9.

25. Seow CY, Pratusevich VR, Ford LE: Series-to-parallel transition in the filament lattice of airway smooth muscle. J Appl Physiol 2000, 89:869-876.

26. Seow CY, Stephens NL: Velocity-length-time relations in canine tracheal smooth muscle. J Appl Physiol 1988, 64:2053-2057.

27. Pratusevich Victor R., Seow Chun Y., Ford Lincoln E.: Plasticity in canine airway smooth muscle. J. Gen. Physiol. 1995, 105:73-94.

28. Otis $A B$ : A perspective of respiratory mechanics. J Appl Physiol 1983, 54:1| $183-1187$. 
29. Mead J: Respiration: pulmonary mechanics. Ann. Rev. Physiol. 1973, 35:169-192.

30. Colebatch HJH, Olsen CR, Nadel JA: Effect of histamine, serotonin, and acetylcholine on the peripheral airways. J. Appl. Physiol. 1966, 21:217-226.

31. Dixon WE, Brodie TG: Contributions to the physiology of the lungs. Part I. The bronchial muscles, their innervation, and the action of drugs upon them. J. Phyisiol. (London) 1903, 29:97-I73.

32. Salter HH: Classic papers in Asthma: On asthma, its pathology and treatment, 1859. The Evolution of Understanding Volume I. Edited by: Brewis RAL. London, Science Press Limited; 1990:106-142.

33. Einthoven W: Ueber die Wirkung der Bronchialmuskeln, nach einer neuen Methode untersucht, und ueber Asthma nervosum. Pfluegers Archives 1892, 5 I:367-444.

34. Oldmixon EH, Carlson K, C. Kuhn III, Butler JP, F.G. Hoppin Jr.: Lung contractility: Disposition, quantities and physiological effects of a-actin in rat and guinea pig lungs. J. Appl. Physiol.

35. Colebatch $\mathrm{HJH}$, Mitchell CA: Constriction of isolated living liquid-filled dog and cat lungs with histamine. J. Appl. Physiol. I971, 30:691-702.

36. Ludwig MS, Dreshaj I, Solway J, Munoz A, Ingram R H, Jr.: Partitioning of pulmonary resistance during constriction in the dog: effects of volume history. J. Appl. Physiol. 1987, 62:807-8I5.

37. Ludwig M, Shore S, Fredberg Jj, Drazen JM: Differential responses of tissue viscance and collateral resistance to histamine and leukotriene C4. J. Appl. Physiol. 1988, 65: | 424-1429.

38. Fredberg JJ, Bunk D, Ingenito E, Shore SA: Tissue resistance and the contractile state of lung parenchyma. J. Appl. Physiol. 1993, 74: 1387-I397.

39. Dolhnikoff M, Morin J, Ludwig MS: Human lung parenchyma responds to contractile stimulation. Am J Respir Crit Care Med 1998, 158:1607-1612.

40. Yager D, Butler JP, Bastacky J, Israel E, Smith G, Drazen JM: Amplification of airway constriction due to liquid filling of airway interstices. J. Appl. Physiol. 1989, 66:2873-2884.

4I. Woolcock AJ, Peat JK: Epidemiology of bronchial hyperresponsiveness. Clin Rev Allergy 1989, 7:245-256.

42. Sterk PJ, Bel EH: Bronchial hyperresponsiveness: the need to distinguish between hypersensitivity and excessive airway narrowing. Eur. Respir. J. 1989, 2:267-274.

43. Armour CL, Black JL, Berend N, Woolcock AJ: The relationship between bronchial hyperresponsiveness to methacholine and airway smooth muscle structure and reactivity. Respir Physiol 1984, 58:223-233.

44. Leckie MJ, ten Brinke A, Khan J, Diamant Z, O'Connor BJ, Walls CM, Mathur AK, Cowley HC, Chung KF, Djukanovic R, Hansel TT, Holgate ST, Sterk PJ, Barnes PJ: Effects of an interleukin-5 blocking monoclonal antibody on eosinophils, airway hyper-responsiveness, and the late asthmatic response. Lancet 2000, 356:2|44-2| 48 .

45. Bryan SA, O'Connor BJ, Matti S, Leckie MJ, Kanabar V, Khan J, Warrington SJ, Renzetti L, Rames A, Bock JA, Boyce MJ, Hansel TT, Holgate ST, Barnes PJ: Effects of recombinant human interleukin12 on eosinophils, airway hyper-responsiveness, and the late asthmatic response. Lancet 2000, 356:2149-2I53.

46. Crimi E, Spanevello A, Neri M, Ind PW, Rossi GA, Brusasco V: Dissociation between airway inflammation and aiway hyperresponsiveness in allergic asthma. Am. J. Respir. Crit. Care Med. 1998 157:4-9.

47. Holloway JW, Beghe B, Holgate ST: The genetic basis of atopic asthma. Clin Exp Allergy 1999, 29:1023-1032.

48. Fernandes DJ, Mitchell RW, Lakser O, Dowell M, Stewart AG, Solway J: Do inflammatory mediators influence the contribution of airway smooth muscle contraction to airway hyperresponsiveness in asthma? J Appl Physiol 2003, 95:844-853.

49. Wang L, Paré PD, Seow CY: Effect of chronic passive length change on airway smooth muscle length-tension relationship. J Appl Physiol 200 I, 90:734-740.

50. Lakser OJ, Lindeman RP, Fredberg J]: Inhibition of the p38 MAP kinase pathway destabilizes smooth muscle length during physiological loading. Am J Physiol Lung Cell Mol Physiol 2002, 282:LIII7-2I.

5I. Tschumperlin DJ, Shively JD, Kikuchi T, Drazen JM: Mechanical stress triggers selective release of fibrotic mediators from bronchial epithelium. Am J Respir Cell Mol Biol 2003, 28: I42-I49.
52. Tschumperlin DJ, Shively JD, Swartz MA, Silverman ES, Haley KJ, Raab G, Drazen JM: Bronchial epithelial compression regulates MAP kinase signaling and HB-EGF-like growth factor expression. Am J Physiol Lung Cell Mol Physiol 2002, 282:L904-I I.

53. Shore SA, Laporte J, Hall IP, Hardy E, Panettieri Jr RA: Effect of ILI beta on responses of cultured human airway smooth muscle cells to bronchodilator agonists. Am J Respir Cell Mol Biol I997, 16:702-712.

54. Halayko AJ, Solway J: Molecular mechanisms of phenotypic plasticity in smooth muscle cells. J Appl Physiol 200I, 90:358-368.

55. Halayko AJ, Morla A, Camoretti-Mercado B, Forsythe S, Vieira JE, Niu Q, Shapiro S, Hershenson MB, Stephens NL, Solway J: Contractile phenotype expession by cultured canine airway myocytes is inhibited by poly-L-lysine and by fibronectin matrix disassembly. Am. J. Resp. Crit. Care. Med. 1998:A656.

56. Small JV: Structure-function relationships in smooth muscle: the missing links. Bioessays 1995, 17:785-792.

57. Small JV, Gimona M: The cytoskeleton of the vertebrate smooth muscle cell. Acta Physiol Scand 1998, 164:34I-348.

58. Huxley AF: Muscle structure and theories of contraction. Prog in Biophys Biophys Chem 1957, 7:255-318.

59. Murphy RA: What is special about smooth muscle? The significance of covalent crossbridge regulation. FASEB J 1994, 8:3II-3I8.

60. Murphy RA: Muscle cells of hollow organs. News in Physiological Sciences 1988, 3:124-I28.

6I. Mijailovich SM, Butler JP, Fredberg JJ: Perturbed equilibria of myosin binding in airway smooth muscle: bond- length distributions, mechanics, and ATP metabolism. Biophys J 2000, 79:2667-268I.

62. Uvelius B: Isometric and isotonic length-tension relations and variations in cell length in longitudinal smooth muscle from rabbit urinary bladder. Acta Physiol Scand 1976, 97:1-12.

63. Stephens NL, Laviolette M, Unruh H, Ma X: Contractility in bronchial airway smooth muscle cells obtained from asthmatic subjects by endobronchial biopsy is increased. American Journal of Respiratory and Critical Care Medicine 1998, I57:A746.

64. Stephens NL: Airway smooth muscle. Am. Rev. Respir. Dis. 1987, 135:960-975.

65. Stephens Newman L., Seow Chun Y.: Airway smooth muscle: Physiology, Bronchomotor Tone, Pharmacology, and relation to Asthma. Bronchial Asthma 1993.

66. $\mathrm{Xu} \mathrm{JQ}$, Harder $\mathrm{BA}$, Uman $\mathrm{P}$, Craig R: Myosin filament structure in vertebrate smooth muscle. J Cell Biol 1996, 134:53-66.

67. Tonino P, Simon M, Craig R: Mass determination of native smooth muscle myosin filaments by scanning transmission electron microscopy. J Mol Biol 2002, 3 I 8:999-1007.

68. Mehta D, Wu M-F, Gunst SJ: Role of contractile protein activation in the length-dependent modulation of tracheal smooth muscle force. Am. J. Physiol. 1996, 270:C243-C252

69. Hai CM: Length-dependent myosin phosphorylation and contraction of arterial smooth muscle. Pflugers Arch 1991, 4 18:564-57|.

70. Gunst SJ, Meiss RA, Wu Ming-Fang, Rowe M: Mechanisms for the mechanical placticity of tracheal smooth muscle. Am. J. Physiol. 1995, 268:C1267-CI276.

7I. Stephens NL, Kromer U: Series elastic component of tracheal smooth muscle. Am. J. Physiol. 1971, 220:1890-1895

72. Warshaw DM, Rees DD, Fay FS: Characterization of crossbridge elasticity and kinetics of cross-bridge cycling force development in single smooth muscle cells. J. Gen. Physiol. 1988, 91:76I-779.

73. Nagase T, Moretto A, Ludwig MS: Airway and tissue behavior during induced constriction in rats: intravenous vs. aerosol administration. J Appl Physiol 1994, 76:830-838.

74. Romero P, Ludwig MS: Maximal methacholine-induced constriction in rabbit lungs: interactions between airways and tissues? J. Appl. Physiol. 199I, 70: 1044-1050.

75. Ding DJ, Martin JG, Macklem PT: Effects of lung volume on maximal methacholine-induced bronchoconstriction in normal humans. Journal of Applied Physiology 1987, 62:1324-1330.

76. Robatto FM, Simard S, Orana H, Macklem PT, Ludwig MS: Effect of lung volume on plateau response of airways and tissue to methacholine in dogs. J. Appl. Physiol. 1992, 73:1908-1913. 
77. Wiggs BR, Hrousis CA, Drazen JM, Kamm RD: On the mechanism of mucosal folding in normal and asthmatic airways. J. Appl. Physiol. 1997, 83:1814-1821.

78. Meiss RA: Influence of intercellular tissue connections on airway muscle mechanics. J Appl Physiol 1999, 86:5-I5.

79. Brown RH, Mitzner W: The myth of maximal airway responsiveness in vivo. J Appl Physiol 1998, 85:2012-2017.

80. Warner David O., Gunst Susan J.: Limitation of maximal bronchoconstriction in living dogs. American Review of Respiratory Disease 1992, I 45:553-560.

8I. Moore BJ, King GG, D'Yachkova Y, Ahmad HR, Pare PD: Mechanism of methacholine dose-response plateaus in normal subjects. Am. J. Respir. Crit. Care Med. I998, I 58:666-669.

82. Moore BJ, Verburgt LM, King GG, Pare PD: Effect of deep inspiration on methacholine dose-response curves in normal subjects. Am. J. Respir. Crit. Care Med. I997, I 56:I278-I 28 I.

83. Fredberg JJ, Shore SA: The unbearable lightness of breathing. J Appl Physiol 1999, 86:3-4.

84. Fish JE, Ankin MG, Kelly JF, Peterman VI: Regulation of bronchomotor tone by lung inflation in asthmatic and nonasthmatic subjects. Journal of Applied Physiology 1981, 50:1079-1086.

85. Nadel Jay A., Tierney Donald F.: Effect of a previous deep inspiration on airway resistance in man. Journal of Applied Physiology 196I, 16:717-719.

86. Lim TK, Pride NB, Ingram Jr. RH: Effects of volume history during spontaneous and acutely induced air-flow obstruction in asthma. Am. Rev. Respir. Dis. 1987, I35:591-596.

87. Skloot Gwen, Permutt Solbert, Togias Alkis: Airway hyperresponsiveness in asthma: a problem of limited smooth muscle relaxation with inspiration. Journal of Clinical Investigation 1995, 96:2393-2403.

88. Solway J, Fredberg J): Perhaps airway smooth muscle dysfunction contributes to asthmatic bronchial hyperresponsiveness afer all. Am. J. Resp.Cell. Mol. Biol. 1997, I 7: I44- I 46.

89. Antonissen LA, Mitchell RW, Kroeger EA, Krepon W, Tse KS, Stephens NL: Mechanical alterations of airway smooth muscle in a canine asthmatic model. J. Appl. Physiol. 1979, 46:68I-687.

90. Fan T, Yang M, Halayko A, Mohapatra SS, Stephens NL: Airway responsiveness in two inbred strains of mouse disparate in IgE and IL-4 production. Am. J. Respir. Cell. Mol. Biol. 1997, I7:156-163.

91. Jiang H, Rao K, Halayko AJ, Liu X, Stephens NL: Ragweed sensitization-induced increase of myosin light chain kinase content in canine airway smooth muscle. Am J Respir Cell Mol Biol 1992, 7:567-573.

92. Thomson RJ, Bramley AM, Schellenberg RR: Airway muscle stereology: implications for increased shortening in asthma. Am. J. Respir. Crit. Care. Med. 1996, I 54:749-757.

93. Fredberg J]: Airway smooth muscle in asthma. Perturbed equilibria of myosin binding. Am J Respir Crit Care Med 2000, | 6 I:SI58-60.

94. Fredberg J): Airway smooth muscle in asthma: flirting with disaster. Eur Respir J 1998, I 2: | 252-1256.

95. Duguet A, Biyah K, Minshall E, Gomes R, Wang CG, Taoudi-Benchekroun $M$, Bates $\mathrm{JH}$, Eidelman $\mathrm{DH}$ : Bronchial responsiveness among inbred mouse strains. Role of airway smooth-muscle shortening velocity. Am J Respir Crit Care Med 2000, I 6 I :839-848.

96. Wang CG, Almirall JJ, Dolman CS, Dandurand RJ, Eidelman DH: In vitro bronchial responsiveness in two highly inbred rat strains. J. Appl. Physiol. I997, 82: I 445- I 452.

97. Ma X, Cheng Z, Kong H, Wang Y, Unruh H, Stephens NL, Laviolette $M$ : Changes in biophysical and biochemical properties of single bronchial smooth muscle cells from asthmatic subjects. Am J Physiol Lung Cell Mol Physiol 2002, 283:LI I8I-9.

98. Fredberg JJ, Inouye D, Miller B, Nathan M, Jafari S, Raboudi SH, Butler JP, Shore SA: Airway smooth muscle, tidal stretches, and dynamically determined contractile states. Am. J. Respir. Crit. Care. Med. 1997, I56:1752-1759.

99. Gump A, Haughney L, Fredberg J: Relaxation of activated airway smooth muscle: relative potency of isoproterenol vs. tidal stretch. J Appl Physiol 200I, 90:2306-2310.

100. Shen X, Gunst S], Tepper RS: Effect of tidal volume and frequency on airway responsiveness in mechanically ventilated rabbits. J. Appl. Physiol. 1997, 83: I 202-1208.

101. Lauzon AM, Tyska MJ, Rovner AS, Freyzon Y, Warshaw DM, Trybus KM: A 7-amino-acid insert in the heavy chain nucleotide bind- ing loop alters the kinetics of smooth muscle myosin in the laser trap. J Muscle Res Cell Motil 1998, 19:825-837.

102. Murphy RA, Walker JS, Strauss JD: Myosin isoforms and functional diversity in vertebrate smooth muscle. Comp Biochem Physiol 1997, I I 7:5 I-60.

103. Dillon PF, Aksoy MO, Driska SP, Murphy RA: Myosin phosphorylation and the cross-bridge cycle in arterial smooth muscle. Science 1981, 2 I I:495-497.

104. Barany Michael: ATPase activity of myosin correlated with speed of muscle shortening. Journal of General Physiology 1967, 50:197-218.

105. Fredberg JJ, Jones KA, Nathan M, Raboudi S, Prakash YS, Shore SA, Butler JP, Sieck GC: Friction in airway smooth muscle: mechanism, latch and implications in asthma. J. Appl. Physiol. 1996, 8 I:2703-27I 2.

106. Hai CM, Murphy RA: Cross-bridge dephosphorylation and relaxation of vascular smooth muscle. Am. J. Physiol. I989, 256:C282-C287.

107. Butler TM, Siegman MJ: Control of cross-bridge cycling by myosin light chain phosphorylation in mammalian smooth muscle. Acta Physiol Scand 1998, 164:389-400.

108. Haeberle JR, Hemric ME: A model for the coregulation of smooth muscle actomyosin by caldesmon, calponin, tropomyosin, and the myosin regulatory light chain. Can J Physiol Pharmacol 1994, 72:1400-1409.

109. Jones KA, Lorenz RR, Prakash YS, Sieck GC, Warner DO: ATP hydrolysis during contraction of permeabilized airway smooth muscle [In Process Citation]. Am J Physiol 1999, 277:L334-42.

I I0. Horowitz A, Menice CB, Laporte R, Morgan KG: Mechanisms of smooth muscle contraction. Physiol. Rev. 1996, 76:967-1003.

I I I. Sanders LC, Matsumura F, Bokoch GM, de Lanerolle P: Inhibition of myosin light chain kinase by p2l-activated kinase [see comments]. Science 1999, 283:2083-2085.

1 12. Kimura K, Ito M, Amano M, Chihara K, Fukata $Y$, Nakafuku M, Yamamori B, Feng J, Nakano T, Okawa K, Iwamatsu A, Kaibuchi K: Regulation of myosin phosphatase by Rho and Rho-associated kinase (Rho- kinase) [see comments]. Science 1996, 273:245-248.

I13. Weber LP, Van Lierop JE, Walsh MP: Ca2+-independent phosphorylation of myosin in rat caudal artery and chicken gizzard myofilaments. J Physiol (Lond) 1999, 5 I 6:805-824.

I 14. Hai CM, Murphy RA: Cross-bridge phosphorylation and regulation of latch state in smooth muscle. Am. J. Physiol. I988, 254:C99-C 106

II5. Hai CM, Murphy RA: Regulation of shortening velocity by cross-bridge phosphorylation in smooth muscle. Am. J. Physiol. 1988, 255:C86-C94.

I 16. Hai CM, Murphy RA: CA2+, crossbridge, phosphorylation, and contraction. Annu. Rev. Physiol. 1989, 5 I:285-298.

II7. Haeberle JR, Trybus KM, Hemric ME, Warshaw DM: The effects of smooth muscle caldesmon on actin filament motility. J. Biol. Chem. 1992, 267:23001-23006.

I 18. Gerthoffer WT, Pohl J: Caldesmon and calponin phosphorylation in regulation of smooth muscle contraction. Can J Physio Pharmacol 1994, 72:1410-1414.

I 19. Huang R, Li L, Guo H, Wang CL: Caldesmon binding to actin is regulated by calmodulin and phosphorylation via different mechanisms. Biochemistry 2003, 42:25 13-2523.

120. Gunst Susan J., Stropp John Q., Service Jennifer: Mechanical modulation of pressure-volume characteristics of contracted canine airways in vitro. Journal of Applied Physiology 1990 68:2223-2229.

121. Gunst S]: Contractile force of airway smooth muscle during cyclical length changes. J Appl Physiol 1983, 55:759-769.

122. Gunst SJ: Effect of length history on contractile behavior of canine tracheal smooth muscle. Am. J. Physiol. 1986, 250:CI46-CI54

123. Sasaki H, Hoppin FG Jr: Hysteresis of contracted airway smooth muscle. J Appl Physiol 1979, 47:| 25 I-I262.

124. Molfino NA, Slutsky AS, Julia-Serda G, Hoffstein V, Szalai JP, Chapman $\mathrm{KR}$, Rebuk AS, Zamel N: Assessment of airway tone in asthma. Am. Rev. Respir. Dis. 1993, I48: | 238-1243.

125. Lim TK, Ang SM, Rossing TH, Ingenito EP, Ingram Jr. RH: The effects of deep inhalation on maximal expiratory flow during inten- 
sive treatment of spontaneous asthmatic episodes. Am. Rev. Respir. Dis. 1989, I 40:340-343.

126. Wheatley JR, Pare PD, Engel LA: Reversibility of induced bronchoconstriction by deep inspiration in asthmatic and normal subjects. Eur. Respir. J. 1989, 2:331-339.

127. Kapsali T, Permutt S, Laube B, Scichilone N, Togias A: Potent bronchoprotective effect of deep inspiration and its absence in asthma. J Appl Physiol 2000, 89:7II-720.

128. Malmberg P, Larsson K, Sundblad BM, Zhiping W: Importance of time interval between FEVI measurements in a methacholine provocation test. Eur. Respir. J. 1993, 6:680-686.

129. Scichilone N, Kapsali T, Permutt S, Togias A: Deep inspirationinduced bronchoprotection is stronger than bronchodilation. Am J Respir Crit Care Med 2000, 162:910-916.

130. Scichilone N, Permutt S, Togias A: The lack of the bronchoprotective and not the bronchodilatory ability of deep inspiration is associated with airway hyperresponsiveness. Am J Respir Crit Care Med 200I, I63:4I3-4I9.

13I. Scichilone N, Pyrgos G, Kapsali T, Anderlind C, Brown R, Permutt S, Togias A: Airways hyperresponsiveness and the effects of lung inflation. Int Arch Allergy Immunol 200I, I 24:262-266.

132. Pare PD, Roberts CR, Bai TR, Wiggs BJ: The functional consequences of airway remodeling in asthma. Monaldi Arch Chest Dis 1997, 52:589-596.

133. Moreno RH, Lisboa C, Hogg JC, Paré PD: Limitation of airway smooth muscle shortening by cartilage stiffness and lung elastic recoil in rabbits. J. Appl. Physiol. 1993, 75:738-744.

134. Irvin CG: Lung volume: a principle determinant of airway smooth muscle function. Eur Respir J 2003, 22:3-5.

135. McClean MA, Matheson MJ, McKay K, Johnson PR, Rynell AC, Ammit AJ, Black JL, Berend N: Low lung volume alters contractile properties of airway smooth muscle in sheep. Eur Respir J 2003, 22:50-56.

136. Colebatch HJ, Finucane KE, Smith MM: Pulmonary conductance and elastic recoil relationships in asthma and emphysema. J Appl Physiol 1973, 34:143-153.

137. Brown RH, Herold C], Hirshman CA, Zerhouni EA, Mitzner W: Individual airway constrictor response heterogeneity to histamine assessed by high-resolution computed tomography. Appl. Physiol. 1993, 74:26 I5-2620.

138. Fredberg JJ, Ingram R H Jr., Castile RG, Glass GM, Drazen JM: Nonhomogeneity of lung response to inhaled histamine assessed with alveolar capsules. J. Appl. Physiol. 1985, 58:1914-1922.

139. Hubmayr RD, Hill MJ, Wilson TA: Nonuniform expansion of constricted dog lungs. J Appl Physiol 1996, 80:522-530.

140. Ludwig M, Bellofiore S, Powell WS, Martin JG: Regional variability in the collateral resistance response to histamine in the dog: effects of cyclooxygenase inhibition. Respiration Physiology 1989, 78:297-308.

14I. Lutchen KR, Gillis H: Relationship between heterogeneous changes in airway morphometry and lung resistance and elastance. J Appl Physiol 1997, 83: I 192-1201.

142. Tepper RS, Shen X, Bakan E, Gunst SJ: Maximal airway responses in mature and immature rabbits during tidal ventilation. $J$. Appl. Physiol. 1995, 79: I 190-I 198.

143. Otis D. R., Jr., Petak F, Hantos Z, Fredberg J], Kamm RD: Airway closure and reopening assessed by the alveolar capsule oscillation technique. J Appl Physiol 1996, 80:2077-2084.

144. Suki B, Barabasi AL, Hantos Z, Petak F, Stanley HE: Avalanches and power-law behaviour in lung inflation. Nature 1994, 368:615-618.

145. Minshall E, Wang CG, Dandurand R, Eidelman D: Heterogeneity of responsiveness of individual airways in cultured lung explants. Can J Physiol Pharmacol 1997, 75:9| I-916.

146. Anafi RC, Wilson TA: Airway stability and heterogeneity in the constricted lung. J Appl Physiol 200 I, 91: I I85- I 192.

147. Anafi RC, Beck KC, Wilson TA: Impedance, gas mixing, and bimodal ventilation in constricted lungs. J Appl Physiol 2003, 94:1003-1011.

148. Macklem PT: Airway obstruction and collateral ventilation. Physiol Rev 1971, 5 1:368-436.

149. Jensen A, Atileh H, Suki B, Ingenito EP, Lutchen KR: Selected contribution: Airway caliber in healthy and asthmatic subjects: effects of bronchial challenge and deep inspirations. J Appl Physiol 200I, $91: 506-515$.
150. Brown RH, Mitzner W: Understanding airway pathophysiology with computed tomograpy. J Appl Physiol 2003, 95:854-862.

151. Mijailovich SM: Dynamics of airway closure: critical smooth muscle activation in normals and asthmatics. Am. J. Respir. Crit. Care Med. 2003, 167:A183.

152. Ikeda K, Mitchell RW, Guest KA, Seow CY, Kirchoff CF, Murphy TM, Leff AR: Ontogeny of shortening velocity in porcine trachealis. A J Physiol 1992:L280-M625.

153. Murphy TM, Mitchell RW, Halayko A, Roach J, Roy L, Kelly EA, Munoz NM, Stephens NL, Leff AR: Effect of maturational changes in myosin content and morphometry on airway smooth muscle contraction. Am J Physiol I99I, 260:L47 I-80.

154. Chitano P, Cox CM, Murphy TM: Relaxation of guinea pig trachealis during electrical field stimulation increases with age. J Appl Physiol 2002, 92: I835-1842.

155. Chitano P, Wang J, Cox CM, Stephens NL, Murphy TM: Different ontogeny of rate of force generation and shortening velocity in guinea pig trachealis. J Appl Physiol 2000, 88: I338-1345.

156. Mitchell RW, Murphy TM, Leff AR: Physiological mechanisms mediating enhanced force generation during development and immune sensitization. Can J Physiol Pharmacol 1992, 70:615-623.

157. Eden E, Mitchell D, Mehlman B, Khouli H, Nejat M, Grieco MH, Turino GM: Atopy, asthma and emphysema in patients with severe alpha-I-antitrypsin deficiency. Am. J. Respir. Crit. Care Med. 1997, 1 56:68-74.

158. Singas E, Lesser M, Spungen AM, Bauman WA, Almenoff PL: Airway hyperresponsiveness to methacholine in subjects with spinal cord injury. Chest 1996, I 10:911-915.

159. Sparrow D, O'Connor GT, Rosner B, Weiss ST: Predictors of longitudinal change in methacholine airway responsiveness among middle-aged and older men: the Normative Aging Study. Am J Respir Crit Care Med 1994, 149:376-38I.

160. Boyer J, Amin N, Taddonio R, Dozor A): Evidence of airway obstruction in children with idiopathic scoliosis. Chest 1996, 109:1532-1535.

161. Camargo C. A., Jr., Weiss ST, Zhang S, Willett WC, Speizer FE: Prospective study of body mass index, weight change, and risk of adult-onset asthma in women [see comments]. Arch Intern Med 1999, I59:2582-2588.

162. Sampson MG, Grassino AE: Load compensation in obese patients during quiet tidal breathing. I Appl Physiol 1983, 55:1269-1276.

163. Shore SA, Rivera-Sanchez YM, Schwartzman IN, Johnston RA: Responses to ozone are increased in obese mice. I Appl Physiol 2003, 95:938-945.

164. Martin RJ: Nocturnal Asthma. Mount Kisco, Futura Publishing Co.; 1993.

165. Martin RJ, Pak J, Irvin CG: Effect of lung volume maintenance during sleep in nocturnal asthma. J Appl Physiol 1993, 75: $1467-1470$

166. Schatz M, Dombrowski MP, Wise R, Thom EA, Landon M, Mabie W, Newman RB, Hauth JC, Lindheimer M, Caritis SN, Leveno KJ, Meis $P$, Miodovnik M, Wapner RJ, Paul RH, Varner MW, O'Sullivan MJ, Thurnau GR, Conway D, McNellis D: Asthma morbidity during pregnancy can be predicted by severity classification. J Allergy Clin Immunol 2003, II 2:283-288.

167. Kelsen SG: Asthma and pregnancy. J Allergy Clin Immunol 2003, I I 2:268-270.

168. Gilroy RJ, Mangura BT, Lavietes MH: Rib cage and abdominal volume displacements during breathing in pregnancy. Am Rev Respir Dis 1988, 137:668-672

169. Gilroy R. J., Jr., Lavietes MH, Loring SH, Mangura BT, Mead J: Respiratory mechanical effects of abdominal distension. I Appl Physiol 1985, 58: 1997-2003.

170. Haley KJ, Drazen JM: Inflammation and airway function in asthma - What you see is not necessarily what you get. Am.J. Respir. Crit. Care Med. 1998, 157:I-3.

171. Gunst SJ, Wu MF: Plasticity of airway smooth muscle stiffness and extensibility: role of length-adaptive mechanisms. J Appl Physiol 200I, 90:74I-749.

172. Gunst SJ, Wu MF, Smith DD: Contraction history modulates isotonic shortening velocity in smooth muscle. Am. J. Physiol. 1993. 265:C467-C476.

173. Kuo KH, Herrera AM, Wang L, Pare PD, Ford LE, Stephens NL, Seow $C Y$ : Structure-function correlation in airway smooth muscle 
adapted to different lengths. Am J Physiol Cell Physiol 2003, 285: C384-90

174. Kuo KH, Wang L, Pare PD, Ford LE, Seow CY: Myosin thick filament lability induced by mechanical strain in airway smooth muscle. J Appl Physiol 200I, 90:I8II.

175. Ford LE, Seow CY, Pratusevich VR: Plasticity in smooth muscle, a hypothesis. Can J Physiol Pharmacol 1994, 72:1320-I324.

176. Naghshin J, Wang L, Pare PD, Seow CY: Adaptation to chronic length change in explanted airway smooth muscle. J Appl Physiol 2003, 95:448-53; discussion 435.

177. Qi D, Mitchell RW, Burdyga T, Ford LE, Kuo KH, Seow CY: Myosin light chain phosphorylation facilitates in vivo myosin filament reassembly after mechanical perturbation. Am J Physiol Cell Physiol 2002, 282:CI298-305.

178. Wang L, Paré PD, Seow CY: Effect of length oscillation on the subsequent force development in swine tracheal smooth muscle. J Appl Physiol 2000, 88:2246-2250.

179. Hirshman CA, Emala CW: Actin reorganization in airway smooth muscle cells involves $\mathbf{G q}$ and $\mathrm{Gi}-2$ activation of Rho. Am J Physiol 1999, 277:L653-6I.

180. An SS, Laudadio RE, Lai J, Rogers RA, Fredberg J]: Stiffness changes in cultured airway smooth muscle cells. Am J Physiol Cell Physiol 2002, 283: C792-801.

18I. Wang P, Bitar KN: Rho A regulates sustained smooth muscle contraction through cytoskeletal reorganization of HSP27. Am J Physiol 1998, 275:G I 454-62.

182. Mehta D, Tang DD, Wu MF, Atkinson S, Gunst SJ: Role of Rho in $\mathrm{Ca}(2+)$-insensitive contraction and paxillin tyrosine phosphorylation in smooth muscle. Am J Physiol Cell Physiol 2000, 279: C308-18.

183. Hedges JC, Yamboliev IA, Ngo M, Horowitz B, Adam LP, Gerthoffer WT: p38 mitogen-activated protein kinase expression and activation in smooth muscle. Am J Physiol 1998, 275:C527-34.

184. Hedges JC, Dechert MA, Yamboliev IA, Martin JL, Hickey E, Weber LA, Gerthoffer WT: A role for P38(MAPK)/HSP27 pathway in smooth muscle cell migration. J Biol Chem 1999, 274:242II-242I9.

185. Hedges JC, Oxhorn BC, Carty M, Adam LP, Yamboliev IA, Gerthoffer WT: Phosphorylation of caldesmon by ERK MAP kinases in smooth muscle. Am J Physiol Cell Physiol 2000, 278:C7I 8-26.

186. Yamboliev IA, Hedges JC, Mutnick JL, Adam LP, Gerthoffer WT: Evidence for modulation of smooth muscle force by the p38 MAP kinase/HSP27 pathway. Am J Physiol Heart Circ Physiol 2000, 278:HI899-907.

187. An S, Fabry B, Mellema M, Bursac P, Gerthoffer WT, Kayyali US, Gaestal M, Shore SA, Fredberg JJ: Role of heat shock protein $\mathbf{2 7}$ in cytoskeletal remodeling of the airway smooth muscle cell. J Applied Physiol in press.

188. Fabry B, Maksym GN, Butler JP, Glogauer M, Navajas D, Taback NA, Millet E], Fredberg I]: Time scale and other invariants of integrative mechanical behavior in living cells. Phys Rev E Stat Nonlin Soft Matter Phys 2003, 68:41914.

189. Gunst S], Fredberg J]: The first three minutes: smooth muscle contraction, cytoskeletal events, and soft glasses. J Appl Physiol 2003, 95:413-425.

190. Fabry B, Fredberg J]: Remodeling of the airway smooth muscle cell: are we built of glass? Respir Physiol Neurobiol 2003, 137:109-124.
Publish with Bio Med Central and every scientist can read your work free of charge

"BioMed Central will be the most significant development for disseminating the results of biomedical research in our lifetime. "

Sir Paul Nurse, Cancer Research UK

Your research papers will be:

- available free of charge to the entire biomedical community

- peer reviewed and published immediately upon acceptance

- cited in PubMed and archived on PubMed Central

- yours - you keep the copyright
BioMedcentral 